\title{
Seven year particulate matter air quality assessment from surface and satellite measurements
}

\author{
P. Gupta and S. A. Christopher \\ Department of Atmospheric Science, The University of Alabama in Huntsville, Huntsville, AL, USA
}

Received: 1 November 2007 - Published in Atmos. Chem. Phys. Discuss.: 9 January 2008

Revised: 15 May 2008 - Accepted: 15 May 2008 - Published: 27 June 2008

\begin{abstract}
Using seven years of the Moderate Resolution Imaging Spectroradiometer (MODIS) aerosol optical thickness (AOT) data and ground measurements of particulate matter mass over one site in the Southeastern United States $\left(33.55^{\circ} \mathrm{N}, 86.82^{\circ} \mathrm{W}\right)$ we present a comprehensive analysis of various aspects of particulate matter air quality. Monthly, seasonal and inter-annual relationships are examined with emphasis on sampling biases, quality indicators in the AOT product and various cloud clearing criteria. Our results indicate that $\mathrm{PM}_{2.5}$ mass concentration over Northern Birmingham has decreased by about $23 \%$ in year 2006 when compared to year 2002 and air quality during summer months was poor when compared to winter months. MODIS-Terra AOT data was available only about $50 \%$ of the time due to cloud cover and unfavorable surface conditions. However, the mean difference in monthly mean $\mathrm{PM}_{2.5}$ was less than $2.2 \mu \mathrm{gm}^{-3}$ derived using all the data and from only those days when satellite AOT was available indicating that satellite data does not have sampling issues. The correlation between $\mathrm{PM}_{2.5}$ and MODIS AOT increased from 0.52 to 0.62 when hourly $\mathrm{PM}_{2.5}$ data were used instead of daily mean $\mathrm{PM}_{2.5}$ data. Changing box size for satellite data around the ground station during comparisons produced less than \pm 0.03 difference in mean AOT values for $90 \%$ of observations. Application of AOT quality flags reduced the sample size but does not affect AOT-PM 2.5 relationship significantly. We recommend using AOT quality flags for daily analysis, whereas long time scale analysis can be performed by using all AOT retrievals to obtain better sampling. Our analysis indicates that satellite data is a useful tool for monitoring particulate matter air quality especially in regions where ground measurements are not available. While these results
\end{abstract}

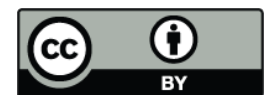

Correspondence to: P. Gupta (gupta@nsstc.uah.edu) are representative for the region of interest, it is difficult to extrapolate these results to a larger context without detailed analysis using ancillary data sets.

\section{Introduction}

Particulate matter (PM or aerosols) is an important component of air pollution, having both long-term as well as shortterm effects on human health such as cardiovascular, lung and skin diseases, which sometimes leads to premature death (Krewski et al., 2000; Pope et al., 2000; HEI, 2004; Pope and Dockery, 2006). Particulate matter assessment is of major concern around the world and many environmental protection agencies are working towards continuous monitoring and assessment of air pollution from surface based stations.

Advancement in satellite remote sensing of aerosols over land since the launch of the Moderate Resolution Imaging SpectroRadiometer (MODIS) has provided a new area of research for monitoring global PM air quality (Gupta et al., 2006). Satellite-derived aerosol optical thickness (AOT) represents integrated atmospheric columnar loading of aerosols and can be used as a surrogate to assess surface particulate matter air quality, especially when surface measurements are not available. Research studies (Engel Cox et al., 2006; Al-Saadi et al., 2005; Gupta et al., 2006, 2007; Pelletier et al., 2007) have shown the potential of using satellite derived AOT values to derive mass concentration of particulate matter with aerodynamic diameter less than $2.5 \mu \mathrm{m}$ $\left(\mathrm{PM}_{2.5}\right)$. Most of these studies have compared MODIS derived AOT with surface measured $\mathrm{PM}_{2.5}$ mass concentration and linear regression equations were formulated to calculate $\mathrm{PM}_{2.5}$ mass concentration over regions where surface measurements were not available. Some studies have used local meteorological parameters along with satellite-derived

Published by Copernicus Publications on behalf of the European Geosciences Union. 
Table 1. MODIS aerosol parameters (MOD04, collection 5) used in the current study.

\begin{tabular}{cll}
\hline No. & Parameter & Description \\
\hline 1 & Latitude & Geodetic latitude of each AOT pixel \\
2 & Longitude & Geodetic longitude of each AOT pixel \\
3 & Solar Zenith & Solar zenith angle corresponding to each pixel \\
4 & Optical Depth Land And Ocean & Aerosol optical thickness at $0.55 \mu$ m for both ocean (best) and land (corrected) \\
5 & Cloud Fraction Land & Cloud cover fraction for each pixel determined by spatial technique (Martin et al., 2002) \\
6 & Cloud Mask QA & Cloud mask quality assurance originally derived at $1 \times 1 \mathrm{~km}^{2}$ that is recomputed at $10 \times 10 \mathrm{~km}^{2}$ \\
& & spatial resolution to determine cloudy and clear pixels, land surface type, sun glint, day $/ \mathrm{night,}$ \\
& & and snow/ice. Stored as 1 byte SDS \\
7 & Quality Assurance Land & Run time quality assurance flag for AOT over land contains product quality flags, retrieval \\
& & processing flags, and input data resource flags. Stores in 5 byte SDS. \\
\hline
\end{tabular}

products to form multiple regression equations that improve overall relationships (e.g. Liu et al., 2004). Other studies, have used the Goddard Earth Observing System (GEOS) Chemistry transport model (GEOS-CHEM) derived vertical profiles to obtain boundary layer aerosol optical thickness, which is converted to surface level $\mathrm{PM}_{2.5}$ mass concentration (Donkelaar et al., 2006).

Satellite based studies indicate that AOT data can be used to monitor $\mathrm{PM}_{2.5}$ pollution over global areas on a near daily basis (Gupta et al., 2006; Chu et al., 2003). Currently, there are several satellites in polar and geostationary orbits that are capable of monitoring aerosols over land from global to regional scales with moderate spatial and temporal resolution. Satellite sensors such as MODIS on Terra and Aqua satellites, Multi-angle Imaging SpectroRadiometer (MISR), POLarization and Directionality of the Earth's Reflectances (POLDER), and Ozone Monitoring Instrument (OMI) are examples of polar orbiting sensors, which provide AOT at 10 to $20 \mathrm{~km}$ spatial resolution. Geostationary satellites such as GOES and METEOSAT have also shown the potential of providing aerosol information on much higher temporal resolution (e.g. Prados et al., 2007). However, most studies use MODIS data, due to its good spatial resolution, excellent ability to mask clouds, and due to its near-daily global coverage. Although MISR derived AOT values proved to be better than MODIS over land (Abdou et al., 2005), MISR's main limitation is its narrow swath $(360 \mathrm{~km})$, allowing for global coverage only every 8 to 9 days thereby limiting its use for air quality studies that require information on daily time scales. Although the MODIS has near daily global coverage, cloud cover and changes in surface properties with season limits the aerosol retrieval on a daily basis.

According to the latest American Lung Association annual air quality report card Birmingham, $\mathrm{AL}$, is ranked as the 4 th most polluted city of the United States for particulate pollution. Therefore, we use MODIS (Terra) derived aerosol products along with surface measured $\mathrm{PM}_{2.5}$ mass concentration over North Birmingham (NBHM) to assess particulate matter quality from daily to yearly scales using various methods.
We focus on a single air quality station (NBHM) and provide detailed air quality analysis considering different aspects of surface and satellite measurements over a seven year time period, which is unique to this research. Previous studies in this region or elsewhere used data for limited time periods and primarily focused on estimation of relationship between $\mathrm{PM}_{2.5}$ and AOT only. In addition to the $\mathrm{PM}_{2.5}$-AOT relationship, we also examine the differences in surface and satellite observations on monthly and yearly time scales. This provides insight into the effects of aerosol quality flags, on data loss, and we finally provide recommendations on using satellite data to derive particulate matter air quality.

\section{Data}

The data sets used in current study can be categorized into satellite and surface observations. The first is the aerosol optical thickness (AOT) data product from Terra-MODIS and the second is daily and $1 \mathrm{~h}$ mean $\mathrm{PM}_{2.5}$ mass concentration measured from ground based air quality station using EPA's AirNow network. Both data sets are obtained for a sevenyear time period (2000-2006).

\subsection{MODIS}

MODIS Level 2 aerosol data (MOD04, Collection 5) from 24 February 2000 to 30 June 2006 were obtained from the Level 1 and Atmosphere Archive and Distribution System (LAADS) at NASA's Goddard Space Flight Center (GSFC). Each MOD04 granule contains the aerosol properties both over land and ocean retrieved from 5 minutes of MODIS observations using updated collection 5 operational algorithms. Detailed descriptions of these improved aerosol algorithms over land are provided by Levy et al. (2007a, b). The main geophysical validated parameters are spectral aerosol optical thickness (AOT), Angstrom exponent (AE), Cloud fraction $(\mathrm{CF})$, and quality flags related to AOT retrieval, cloud masking, and surface types. Table 1 lists the parameters that are used in the current study. We also apply various quality 
Table 2. Criteria used to obtain coincident MODIS - Terra AOT data over $\mathrm{PM}_{2.5}$ locations.

\begin{tabular}{cccccc}
\hline \multicolumn{7}{c}{ Quality Flags } \\
\hline Criteria No. & Box size around ground stations & Surface type & SZA $^{*}(\mathrm{deg})$ & AOT Flag & Cloud Flag \\
\hline 1 & $\pm 0.25 \mathrm{deg} .(\sim 5 \times 5$ pixels $)$ & - & - & - & - \\
2 & $\pm 0.20 \mathrm{deg} .(\sim 4 \times 4$ pixels $)$ & - & - & - & - \\
3 & $\pm 0.15 \mathrm{deg} .(\sim 3 \times 3$ pixels $)$ & - & - & - & - \\
4 & $\pm 0.15 \mathrm{deg} .(\sim 3 \times 3$ pixels $)$ & Land & $\leq 60$ & - & - \\
5 & $\pm 0.15 \mathrm{deg} .(\sim 3 \times 3$ pixels $)$ & Land & $\leq 60$ & - & $0-90 \%$ \\
6 & $\pm 0.15 \mathrm{deg} .(\sim 3 \times 3$ pixels $)$ & Land & $\leq 60$ & - & $0-60 \%$ \\
7 & $\pm 0.15 \mathrm{deg} .(\sim 3 \times 3$ pixels $)$ & Land & $\leq 60$ & - & $0-30 \%$ \\
8 & $\pm 0.15 \mathrm{deg} .(\sim 3 \times 3$ pixels $)$ & Land & $\leq 60$ & G \& VG & - \\
9 & $\pm 0.15 \mathrm{deg} .(\sim 3 \times 3$ pixels $)$ & Land & $\leq 60$ & G \& VG & $0-30 \%$ \\
\hline
\end{tabular}

*SZA: Solar Zenith Angle, AOT: Aerosol Optical Thickness

flags associated with cloud masking and AOT retrieval to estimate the difference in mean AOT values with that obtained from standard collocation (Ichoku et al., 2002) and analysis methods (Wang and Christopher, 2003) that do not use quality flags. While obtaining coincident MODIS pixels with the $\mathrm{PM}_{2.5}$ measurements, nine different criteria are applied to evaluate AOT product for $\mathrm{PM}_{2.5}$ air quality applications (Table 2). In order to understand these criteria, a brief discussion of MODIS collection 5 land aerosol retrieval is provided.

The MODIS land aerosol algorithm initially retrieves AOT in two wavelengths $(0.446$ and $0.667 \mu \mathrm{m})$ and AOT at $0.55 \mu \mathrm{m}$ is obtained by interpolating between these two wavelengths. The algorithm also uses the $2.1 \mu \mathrm{m}$ channel along with the vegetation index to obtain surface reflectance (Levy et al., 2007a) and other channels to mask cloudy pixels from each $5 \mathrm{~min}$ MODIS granule. Although the retrieved AOT values are reported at a $10 \times 10 \mathrm{~km}^{2}$ pixel resolution, the algorithm initially uses radiance measurements at much higher resolution of $0.5 \times 0.5 \mathrm{~km}^{2}$. All 400 pixels $(20 \times 20$ pixels $)$, each having resolution of $0.5 \times 0.5 \mathrm{~km}^{2}$ within the $10 \times 10 \mathrm{~km}^{2}$ area, are first examined for cloud contamination using a spatial distribution technique (Martin et al., 2002). The MODIS internal cloud mask (Ackerman et al., 1998) at $1 \times 1 \mathrm{~km}^{2}$ spatial resolution is also used to identify cirrus. All pixels identified as cloudy are removed and further analysis uses only cloud free pixels to retrieve AOT. Once cloud free pixels are identified, the mean reflectance is calculated from these pixels to retrieve AOT. The measured mean reflectance is matched with lookup tables of calculated reflectance for various aerosol models to obtain aerosol properties for each $10 \times 10 \mathrm{~km}^{2}$ pixel. Levy et al. (2007a) provide further details.

The percentage of cloudy pixels in a $10 \times 10 \mathrm{~km}^{2}$ grid is computed using $1 \times 1 \mathrm{~km}^{2}$ cloud mask after applying specific thresholds that are represented in terms of cloud mask quality flags (Cloud_Mask_QA). This Cloud_Mask_QA (CMQA) flag is stored as 8-bit information, which includes percentage cloudy pixels, snow/ice flags and surface type information (Hubanks et al., 2007). In this study, we have used quality control flags listed in criterion 4 through 9 (Table 2) to determine the importance of cloud contamination on AOT and how it affects AOT calculations for particulate matter air quality research. Aerosol retrieval quality flags (Quality Assurance Land or QAL) can also be an important factor on whether or not the retrieved AOT should be matched up with the $\mathrm{PM}_{2.5}$ mass measurements from the ground. This flag contains 40 bits of information, which includes confidence level of retrieval, quality of AOT at both wavelengths (no confidence, marginal, good, or very good), surface reflectance criteria used in retrieval, aerosol types, thin cirrus detection, ozone, water vapor, and snow cover data sources, and other flags associated with the deep blue algorithm (Hsu et al., 2004) In this study, we have used product quality flags from QAL as criteria numbers 8 and 9 (Table 2), which shows confidence level of AOT retrieval at two wavelengths.

\subsection{Particulate matter mass $\left(\mathrm{PM}_{2.5}\right)$}

Particulate matter mass concentration $\left(\mu \mathrm{gm}^{-3}\right)$ with aerodynamic diameter less than $2.5 \mu \mathrm{m}\left(\mathrm{PM}_{2.5}\right)$ is regularly monitored by United States Environment Protection Agency (USEPA). The particulate matter air quality in the Continental United States is evaluated based on the $\mathrm{PM}_{2.5}$ mass concentration measured using a network of surface stations. Generally, a Tapered Element Oscillating Microbalance (TEOM) instrument is used to measure the mass of $\mathrm{PM}_{2.5}$ particles in units of $\mu \mathrm{gm}^{-3}$. The EPA and its state partners maintain several air quality monitoring networks in the United States. These networks monitor the mass concentration and speciation (some sites) of gaseous and particulate air pollutants near the surface. $\mathrm{PM}_{2.5}$ data from these networks include $24 \mathrm{~h}$ average (daily) concentration data and continuous (hourly) $\mathrm{PM}_{2.5}$ mass concentration measurements. We use $\mathrm{PM}_{2.5}$ data from the North Birmingham 
(NBHM, $33.55 \mathrm{~N}$ and $86.82 \mathrm{~W}$ ) station located in Jefferson County, Alabama, which has a data availability of $85 \%$ for any given year. Figure 1 shows a detailed view of the stations along with larger view of the EPA region 4.

\section{Methodology}

To obtain coincident $\mathrm{PM}_{2.5}$ and MODIS AOT values at NBHM, nine different criteria are applied (Table 2). Mean AOT for each day and each criterion is obtained over almost a seven year time period. The spatial resolution of one MODIS AOT pixel is approximately $10 \times 10 \mathrm{~km}^{2}$, whereas surface measurements are point values thereby making intercomparisons difficult. Even if the MODIS pixel was small enough, it does not represent the same viewing conditions due to differences between observation areas, varying path lengths through the atmosphere, and sensor sensitivity to aerosol properties. Ichoku et al. (2002) averaged level 2 MODIS AOT pixels using a $5 \times 5$ pixel box over the surface measurement locations and 15-min observations over one hour to represent a similar air mass as observed by MODIS. This was justified by examining the normal speed of aerosol transport $(50 \mathrm{~km} / \mathrm{h})$ using animation of the Total Ozone Mapping Spectrometer (TOMS) imagery over the Atlantic Ocean. This method is used by most satellite aerosol retrieval comparisons with ground measurements (e.g. Remer et al., 2005; Kahn et al. 2005; Abdou et al., 2005).

In the current study, three different box sizes (Fig. 1) centered on NBHM are evaluated to verify the assumptions used in Ichoku et al. (2002). Table 2 provides all nine criteria used to obtain MODIS AOT. Criteria numbers 1 to 3 represents box sizes of $5 \times 5,4 \times 4$, and $3 \times 3$ MODIS pixels around the surface station respectively. It is important to note that in this section, AOT values are obtained for all three conditions without applying any quality flags on MODIS AOT since this is the standard practice in most studies (e.g. Wang and Christopher, 2003) that performed such AOT-PM 2.5 matches.

Criteria numbers 4 to 9 use the $3 \times 3$ pixel box size and apply different quality flags on surface type, solar zenith angle, cloud mask quality and quality of retrieved AOT values. Criteria 4 ensures that all the pixels used in averaging AOT over surface stations are retrieved over land surface with solar zenith angles less than $60^{\circ}$. In some instances there could be inland water pixels, which can create problems in retrieval process or pixels with highly reflecting surfaces might be associated large uncertainty in AOT values (Hutchinson et al., 2005). Large values of solar zenith angle imply long path length through the atmosphere, increasing the probability of diffuse scattering, which makes estimation of path radiance and atmospheric correction challenging.

Criteria numbers 5 to 7 add the quality flags associated with cloud cover (CMQA) in the $10 \times 10 \mathrm{~km}^{2}$ MODIS pixel. Cloud mask quality flags are associated with percentage area of $10 \times 10 \mathrm{~km}^{2}$ pixel covered with clouds based on MODIS $1 \mathrm{~km}$ operational cloud mask product (Ackerman et al., 1998). Criteria 5 allows maximum MODIS pixels for calculating mean value with up to $90 \%$ cloud cover, which is reduced to $60 \%$ and $30 \%$ for criteria 6 and 7 respectively. As the cloud cover criteria is made more stringent, the available number of pixels decreases for calculating mean AOT value, while at the same time the quality of the AOT value increases. However, reducing the number of pixels may also introduce sampling bias into the mean AOT value.

Criteria number 8 corresponds to confidence in AOT retrieval, which is based on number of pixels (with $500 \mathrm{~m}$ resolution) used in retrieving AOT at $10 \mathrm{~km}$ resolution (QAL). Based on the number of pixels used in calculating mean reflectance to retrieve AOT value, each AOT value is flagged as "Good" or "Very Good". Good and Very Good retrievals for both 0.47 and $0.67 \mu \mathrm{m}$ channels are considered for this criterion in addition to those used by criteria 4 (Table 2). Criteria 9 applies all of the restrictions of criteria number 8 plus, it allows only those pixels for which AOT retrieval is done under less than $30 \%$ cloud cover. Criteria 9 uses only the best retrieval situations with all quality flags whereas criteria number 3 represents all retrievals with no quality flags applied to AOT. Collocated AOT values for each of these criteria are tested and correlated with surface measured $\mathrm{PM}_{2.5}$ mass concentration to evaluate the long term change in AOT values as well as $\mathrm{PM}_{2.5}$ mass concentration.

\section{Results}

Results are divided into 4 different sections. Section one discusses the multi-year trends in $\mathrm{PM}_{2.5}$ mass concentration, $\mathrm{PM}_{2.5}$ air quality and MODIS AOT over NBHM. Daily, monthly, seasonal, and annual trends along with frequency distribution of air quality conditions over this site are rigorously examined. The next section explores the availability of MODIS-Terra AOT data over the entire study period and discusses the differences due to satellite sampling in monthly, seasonal, and annual mean $\mathrm{PM}_{2.5}$ mass concentration. This section answers the question of how well satellite sampling (due to cloud cover and other issues) compares with surface measurements (that make continuous measurements regardless of cloud cover) on monthly to yearly time scales. Section three examines the relationship between MODIS AOT and $\mathrm{PM}_{2.5}$ mass concentration on hourly, daily, monthly, and annual basis. This section also evaluates the stability of AOT$\mathrm{PM}_{2.5}$ relationships during different seasons and years. The final section, which is unique to the current study, is evaluation of MODIS AOT for $\mathrm{PM}_{2.5}$ research by considering sampling issues as well as quality flags associated with each retrieved AOT pixel. This section also revisits the results of section 1 to 3 under these new criteria for obtaining satellite observations and discusses the differences in AOT and $\mathrm{PM}_{2.5}$ that arise when using stringent quality flags. 


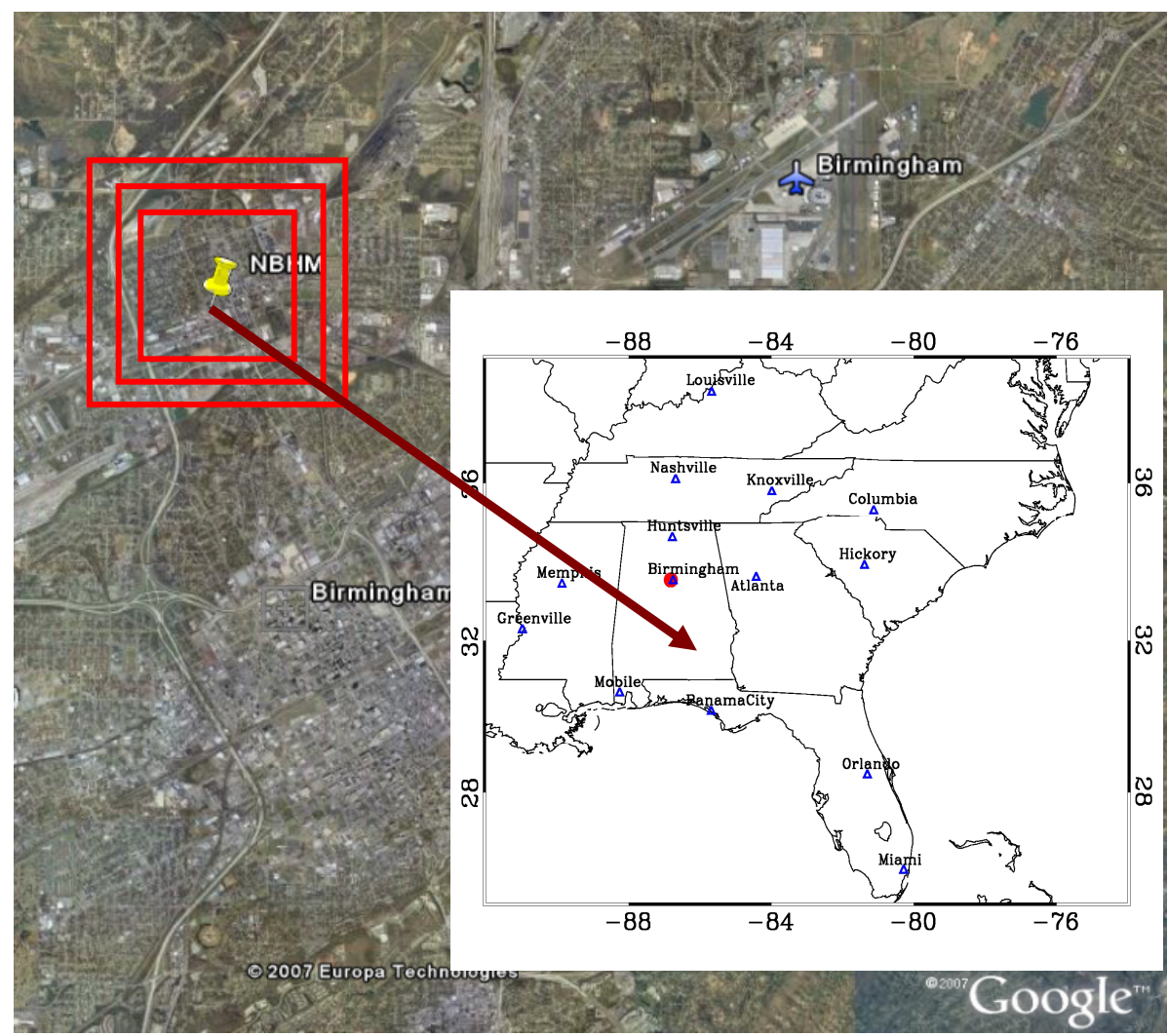

Fig. 1. Study area with location of $\mathrm{PM}_{2.5}$ ground stations in Birmingham, AL. Also shown is a zoomed satellite image (courtesy Google) of the region with 3 different box sizes used to collocate MODIS observations.

\subsection{Long term air quality trends over North Birmingham}

Surface measured $\mathrm{PM}_{2.5}$ mass concentration from NBHM and MODIS AOT from the Terra spacecraft are both continuously available starting in February 2000. Therefore, we have almost seven years of data to analyze daily, monthly, seasonal and annual trends in air quality and aerosol loading over NBHM. Figure 2 shows the time series of $24 \mathrm{~h}$ mean $\mathrm{PM}_{2.5}$ mass concentration along with monthly and annual mean trends. Daily variations in $\mathrm{PM}_{2.5}$ mass are represented by thin light gray line, which are mainly associated with local meteorological conditions and changes in local emissions of $\mathrm{PM}_{2.5}$ particles. High values could also be associated with transport of pollution from surrounding areas. The background colors denote the air quality conditions as defined by USEPA based on mass concentration of aerosol particles that are smaller than $2.5 \mu \mathrm{m}$ in aerodynamic diameter. The horizontal red line corresponding to $15 \mu \mathrm{gm}^{-3}$ and $35 \mu \mathrm{gm}^{-3}$ are the annual and $24 \mathrm{~h}$ mean national standards set by USEPA under National Ambient Air
Quality Standards (NAAQS), while the previous (prior to prior to 17 December 2006) $24 \mathrm{~h}$ standard of $65 \mu \mathrm{gm}^{-3}$ is also plotted for comparison purposes (Fig. 2). Our analysis indicates that NBHM often experiences moderate to unhealthy air quality conditions for sensitive groups, but rarely reaches the unhealthy category even under the new guidelines. The maximum $24 \mathrm{~h}$ mean $\mathrm{PM}_{2.5}$ mass concentration of $75.3 \mu \mathrm{gm}^{-3}$ was observed on 25 October 2000 whereas the average of all daily mean values is $18.7 \pm 9.7 \mu \mathrm{gm}^{-3}$. The thick gray line presents the monthly mean $\mathrm{PM}_{2.5}$ mass concentration calculated using daily mean values. The monthly mean values clearly show a seasonal trend with high values in spring-summer and low values in fall-winter months. High spring-summer values partially correspond to increase in gas to particle conversion in the atmosphere with increasing available solar radiation, enhancing the photo chemical reactions responsible for such particle production. Similar conditions do not occur in the winter months, thereby limiting $\mathrm{PM}_{2.5}$ production. Seasonal changes in local meteorology also affect the $\mathrm{PM}_{2.5}$ production and removal processes. 


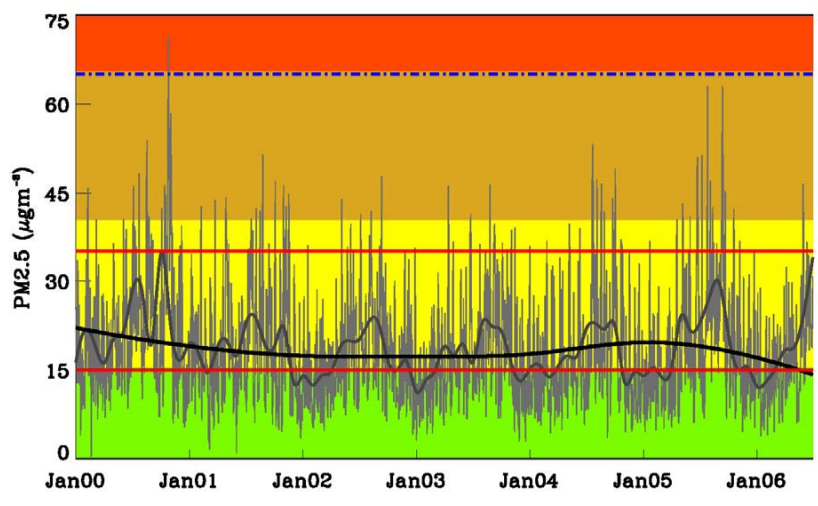

Fig. 2. Time series analysis of $\mathrm{PM}_{2.5}$ mass concentration over NBHM site starting from January 2000 to June 2006. Background colors show air quality categories. Daily variations are shown in thin light gray line, monthly mean in thick gray line and yearly means are shown in thick black line. Two red lines show new daily and annual national standard for $\mathrm{PM}_{2.5}$ mass whereas dotted blue line shows old annual USEPA standards.

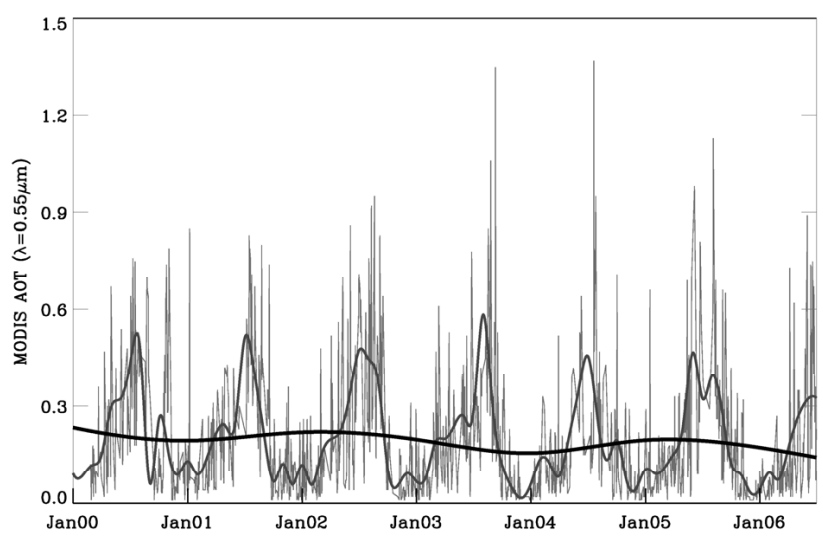

Fig. 3. Time series analysis of MODIS AOT over NBHM from 24 February, 2000 to June 2006. Daily variations are represented by thin light gray line, monthly mean represented by thick gray line and yearly means are shown as thick black line. These results are from criteria number one.

The month-to-month variation is not similar in all the years and varies slightly with peak values around July-August. Monthly mean $\mathrm{PM}_{2.5}$ mass peaks at $34.6 \mu \mathrm{gm}^{-3}$ during October 2000 with a minimum value of $11.3 \mu \mathrm{gm}^{-3}$ observed in January 2003. A weak decreasing trend in annual $\mathrm{PM}_{2.5}$ was noted with the highest and lowest $\mathrm{PM}_{2.5}$ mass concentration of $22.1 \mu \mathrm{gm}^{-3}$ and $17.0 \mu \mathrm{gm}^{-3}$ observed in 2002 and 2006 respectively.

Figure 3 presents similar analysis for AOT derived from MODIS using criteria 1 from Table 2. Recall that this criterion includes all AOT data without any quality flags. The MODIS AOT shows similar trends with high values during summer and low values during winter months. Seasonal changes in AOT are more prominent compared to seasonal changes in $\mathrm{PM}_{2.5}$ mass concentration due to sensitivity of urban aerosols towards relative humidity (Wang et al., 2007). The absolute difference in $\mathrm{PM}_{2.5}$ mass from winter to summer is not as high (when compared to $\mathrm{PM}_{2.5}$ trends in Fig. 2) as observed in MODIS AOT. Recall that AOT is an optical property which is function of light scattering from the aerosol particle and it increases in summer time due to particle growth under high humid conditions (Hess et al., 1998). Therefore, the same aerosol mass can produce large AOT values during summer months compared to winter months. On the other hand, $\mathrm{PM}_{2.5}$ mass does not change significantly due to growth of particles as TEOM make measurement of dry particles under about $40 \%$ relative humidity conditions. MODIS AOT also shows overall decreasing trend in annual mean values over study period.

Figure 4 presents frequency distribution (days of occurrence) of air quality conditions during each month. Also shown are days of occurrence $(\%)$ for each month (secondary $\mathrm{y}$-axis) averaged over all 7 year time period shown as filled circle and interpolated lines. During October 2000, air quality conditions were unhealthy corresponding to the month of highest $\mathrm{PM}_{2.5}$ mass concentration. Frequency of a particular air quality condition shows large variability, but does indicate the presence of a seasonal cycle. Monthly means clearly show that December had the highest frequency of days with good air quality $(\sim 65 \%)$. The frequency of good air quality begins to decrease in January and generally continues to decrease until August when only 23\% of the days have good air quality conditions. Starting September, the air quality condition improves again until December. Moderate air quality conditions occurred $61-68 \%$ of the time during the months of July and August with the lowest (35-37\%) occurring during December and January. Air quality degrades to unhealthy for sensitive group (USG) category on rare occasions and accounts for 9\% days during August, whereas it remains less than $2-3 \%$ for other months. Seasonal variations in primary emissions and secondary formation (gas to particle) rates lead to seasonal differences in $\mathrm{PM}_{2.5}$ concentration. Day to day variations in $\mathrm{PM}_{2.5}$ mass concentrations is usually associated with variations in local meteorological conditions. Meteorological conditions that strongly control $\mathrm{PM}_{2.5}$ mass concentration include change in available sunlight due to clouds and season, vertical mixing of air pollution within atmospheric boundary layer, temperature, moisture, long and short range transport by winds and recirculation of air mass by local wind pattern. Very high level of pollution can be observed during strong temperature inversion near surface (Kukkonen et al., 2005) and the magnitude, vertical structure, and temporal evolution of inversions influence the air quality (Hussein et al., 2006).

\subsection{Availability of satellite data for air quality}

Since the launch of MODIS onboard Terra, almost daily global coverage of AOT retrievals are available and has been 


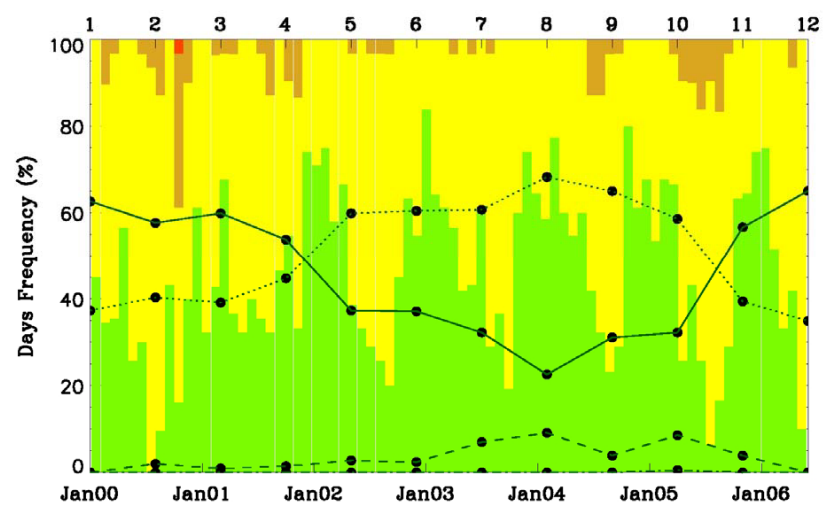

Fig. 4. Frequency distribution of number of days (\%) falling in any particular air quality category during each month over NBHM starting from February 2000 to June 2006. Air quality categories are derived from $\mathrm{PM}_{2.5}$ mass concentration as defined by USEPA and represented by different colors. Green is good air quality, Yellow is moderate, Orange is Unhealthy for sensitive groups, and Red is Unhealthy. Mean frequency for each month over all years is presented as line and open circle for each air quality category and plotted on top axis. Solid line: Good, dotted line: Moderate, dash line: unhealthy for sensitive groups.

used for various climate and air quality research applications. Retrieval of AOT is limited to a cloud-free atmosphere for certain surface conditions, since MODIS cannot retrieve AOT over bright targets such as desert and bright urban centers (Levy et al., 2007a). Advances in observation capabilities of satellites and improved retrieval techniques are slowly removing these limitations (Hsu et al., 2004).

In this section we explore the following question: "How well can MODIS Terra AOT data represent monthly and yearly mean $\mathrm{PM}_{2.5}$ mass concentration over NBHM". To answer this question, we assume that $\mathrm{PM}_{2.5}$ mass can be estimated using MODIS AOT data. To test this assumption, daily mean $\mathrm{PM}_{2.5}$ measurements are collocated with MODIS AOT data according to criteria 1 as given in Table 2. Although the Terra satellite overpasses NBHM site almost every day around 10:30 am local time, AOT retrieval may not be available on a daily basis due to clouds and other limitations (e.g. bright surface during certain seasons). Figure 5a presents the number of days (\%) in each month for which AOT data available over the past seven years. The seven-year mean value is $47 \%$, but with significant monthly variability. The numbers of available AOT days are mainly associated with cloud free days over the surface station. Terra-MODIS monthly mean daytime cloud cover data reveals that mean fractional cloud cover was 55\% in the region. Over the entire study period the maximum number of available days was 90\% during October 2000 whereas the minimum was about 7\% during August 2005. Number of available days do not show significant seasonal trends but demonstrate high values during fall and winter and low values in spring and summer

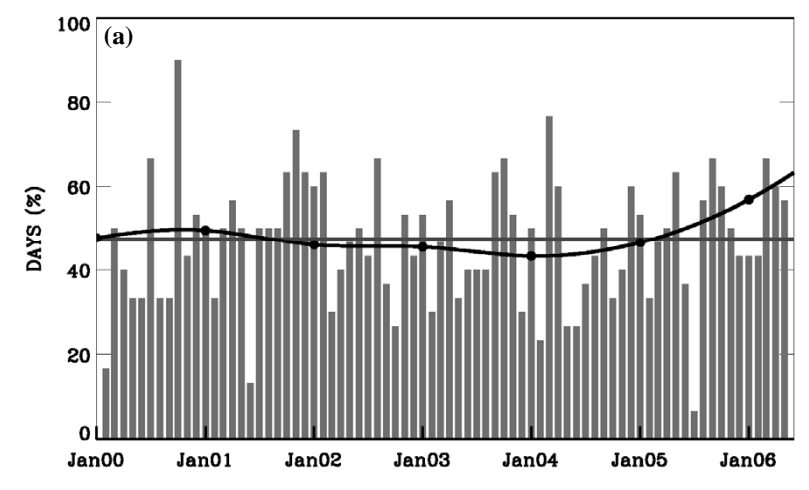

10 (b)

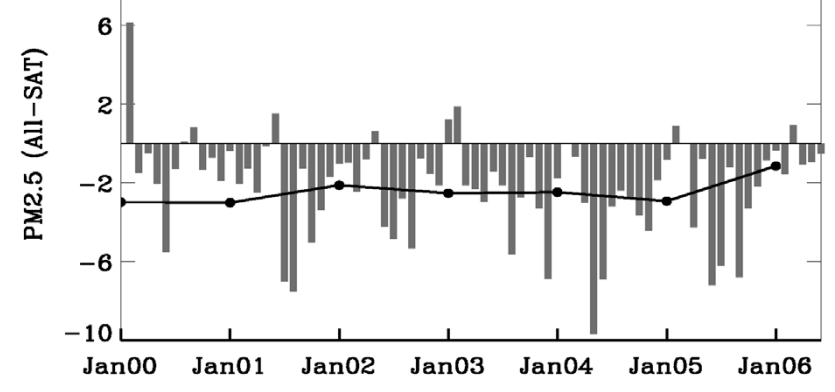

Fig. 5. Time series analysis of difference in $\mathrm{PM}_{2.5}$ mass over NBHM site starting from February, 2000 to June 2006. (a) number of days (\%) MODIS AOT data are available over NBHAM and (b) the monthly mean $\mathrm{PM}_{2.5}$ mass from all ground observation minus $\mathrm{PM}_{2.5}$ mass from only those days when MODIS AOT data are available. Solid line with filled circle shows yearly mean values. Horizontal thick black line in panel (a) is for all time mean values corresponding to $47.4 \%$.

months. Month to month changes in available days vary from maximum of $57 \%$ during October to minimum of $35 \%$ in February averaged over all seven year time period. Tracking number of days in each year is important while evaluating long term trends.

Figure $5 \mathrm{~b}$ presents the monthly mean difference in $\mathrm{PM}_{2.5}$ mass concentration between all 24-h mean $\mathrm{PM}_{2.5}$ measurements averaged for each month (ALL) and $\mathrm{PM}_{2.5}$ measurements averaged only when MODIS Terra AOT is available over the measurement site (SAT). The purpose of this analysis is to evaluate how well satellite measurements can represent monthly and year mean values of $\mathrm{PM}_{2.5}$ mass. Negative differences indicate that using $\mathrm{PM}_{2.5}$ data during the time of the satellite overpass overestimates $\mathrm{PM}_{2.5}$ on monthly as well as yearly basis. This indicates that events with low aerosol (or PM) loading over NBHM are being removed, possibly due to cloud cover. This trend is consistent over the entire study period.

There is only 8 out of 77 months, when this difference is positive, and $50 \%$ of them fall in the winter season. The mean difference is $-2.2 \mu \mathrm{gm}^{-3}$ with maximum negative value of $-9.7 \mu \mathrm{gm}^{-3}$ during May 2004 . 
Table 3. Regression coefficients, mean and standard deviation $(\sigma)$ of $\mathrm{PM}_{2.5}$ and MODIS AOT using criteria number 1.

\begin{tabular}{lllllllll}
\hline & Slope & Intercept & $R$ & Counts & PM $_{2.5}$ & $\sigma$ & AOT & $\sigma$ \\
\hline Year & & & & & & & & \\
\hline 2000 & 35.81 & 16.62 & 0.58 & 147 & 25.09 & 12.63 & 0.24 & 0.21 \\
2001 & 28.95 & 16.39 & 0.50 & 181 & 22.02 & 10.95 & 0.20 & 0.19 \\
2002 & 21.27 & 14.78 & 0.51 & 167 & 19.50 & 9.35 & 0.22 & 0.22 \\
2003 & 22.36 & 15.43 & 0.50 & 165 & 19.88 & 9.65 & 0.20 & 0.22 \\
2004 & 25.52 & 16.18 & 0.46 & 158 & 20.16 & 10.41 & 0.16 & 0.19 \\
2005 & 32.13 & 16.33 & 0.57 & 169 & 22.67 & 11.71 & 0.20 & 0.21 \\
2006 & 26.36 & 13.67 & 0.60 & 103 & 18.23 & 8.58 & 0.17 & 0.20 \\
\hline Mean & 27.48 & 15.63 & 0.53 & 156 & 21.08 & - & 0.20 & - \\
\hline Month & & & & & & & & \\
\hline 1 & 18.34 & 13.28 & 0.29 & 92 & 14.93 & 7.60 & 0.09 & 0.12 \\
2 & 8.55 & 14.04 & 0.08 & 73 & 14.78 & 7.35 & 0.09 & 0.07 \\
3 & 12.03 & 14.43 & 0.17 & 110 & 15.91 & 7.73 & 0.12 & 0.11 \\
4 & 29.11 & 14.33 & 0.44 & 109 & 19.18 & 9.59 & 0.17 & 0.15 \\
5 & 24.91 & 15.43 & 0.51 & 92 & 21.59 & 8.80 & 0.25 & 0.18 \\
6 & 19.10 & 18.08 & 0.46 & 82 & 24.45 & 9.74 & 0.33 & 0.23 \\
7 & 25.82 & 15.20 & 0.57 & 73 & 26.31 & 10.61 & 0.43 & 0.24 \\
8 & 20.54 & 19.13 & 0.49 & 87 & 27.87 & 9.52 & 0.43 & 0.23 \\
9 & 28.81 & 19.61 & 0.56 & 90 & 26.52 & 11.47 & 0.24 & 0.23 \\
10 & 50.59 & 18.72 & 0.64 & 101 & 26.60 & 13.03 & 0.16 & 0.16 \\
11 & 47.90 & 16.02 & 0.49 & 94 & 20.35 & 11.52 & 0.09 & 0.12 \\
12 & -14.34 & 17.98 & -0.11 & 87 & 17.14 & 8.17 & 0.06 & 0.06 \\
\hline Mean & 22.61 & 16.35 & 0.38 & 91 & 21.30 & 9.59 & 0.20 & 0.16 \\
\hline
\end{tabular}

The maximum positive difference of $6.1 \mu \mathrm{gm}^{-3}$ was obtained during February 2000 since Terra-MODIS started observations on 24 February 2000 and only 5-6 days of data available during this month. Averaging each month separately over the entire seven year time period we find that January has minimum negative difference of $-0.5 \mu \mathrm{gm}^{-3}$ whereas February has a positive difference of $0.6 \mu \mathrm{gm}^{-3}$ Again, summer months have large negative differences compared to winter months, which corresponds to more number of available days in winter and less during summer months (Table 3). The solid line with dots in Fig. 4b shows the yearly mean values, which are always negative. The maximum difference $\left(-3.0 \mu \mathrm{gm}^{-3}\right)$ in annual mean is was in 2001 whereas minimum difference $\left(-1.2 \mu \mathrm{gm}^{-3}\right)$ was during 2006.

\subsection{Regression analysis between $\mathrm{PM}_{2.5}$ and MODIS AOT}

Particulate matter air quality monitoring from satellite is based on the relationship between satellite derived AOT and surface measured $\mathrm{PM}_{2.5}$ mass concentration (Wang and Christopher, 2003; Gupta et al., 2006). The accuracy of satellite estimated $\mathrm{PM}_{2.5}$ over any given location depends on the robustness of the regression relationship between AOT and $\mathrm{PM}_{2.5}$ mass, which can depend on the accuracies of retrieved AOT and other factors such as vertical distribution of aerosols. Local meteorological conditions also govern the
$\mathrm{PM}_{2.5}$ mass concentration and hence their inclusion in the AOT $-\mathrm{PM}_{2.5}$ relationship can improve the overall accuracies in $\mathrm{PM}_{2.5}$ mass estimation from satellite observations (Gupta et al., 2006). However, we do not attempt to add meteorological parameters to the analysis for this research.

Computation of a single-variate least-squares linear regression relationship between MODIS AOT and $\mathrm{PM}_{2.5}$ is performed. We now discuss the change in regression coefficient such as slope $(m)$, intercepts $(c)$, linear correlation coefficient $(r)$ and number of collocated points $(N)$ as a function of month, season and year over NBHM. Changes in these parameters between hourly averaged and $24 \mathrm{~h}$ averaged $\mathrm{PM}_{2.5}$ are explored. Figure 6a presents the month to month and annual variations of MODIS AOT (primary y-axis) along with daily mean $\mathrm{PM}_{2.5}$ mass concentration (secondary y-axis). Both MODIS AOT and $\mathrm{PM}_{2.5}$ mass concentration follow similar trends on monthly and yearly time scales as noted in Section 4.1. Figure 5b shows hourly averaged (red lines) $\mathrm{PM}_{2.5}$ during Terra MODIS overpass time from 2000 to 2006 along with $24 \mathrm{~h}$ averaged $\mathrm{PM}_{2.5}$ (blue lines). Both hourly and $24 \mathrm{~h}$ values follow similar variations on monthly and yearly scales, but hourly averaged values are smaller compared to $24 \mathrm{~h}$ averaged values. The mean ratio of monthly mean obtained using $24 \mathrm{~h}$ averages to mean obtained using hourly average $\mathrm{PM}_{2.5}$ is $1.66 \pm 0.47$. 

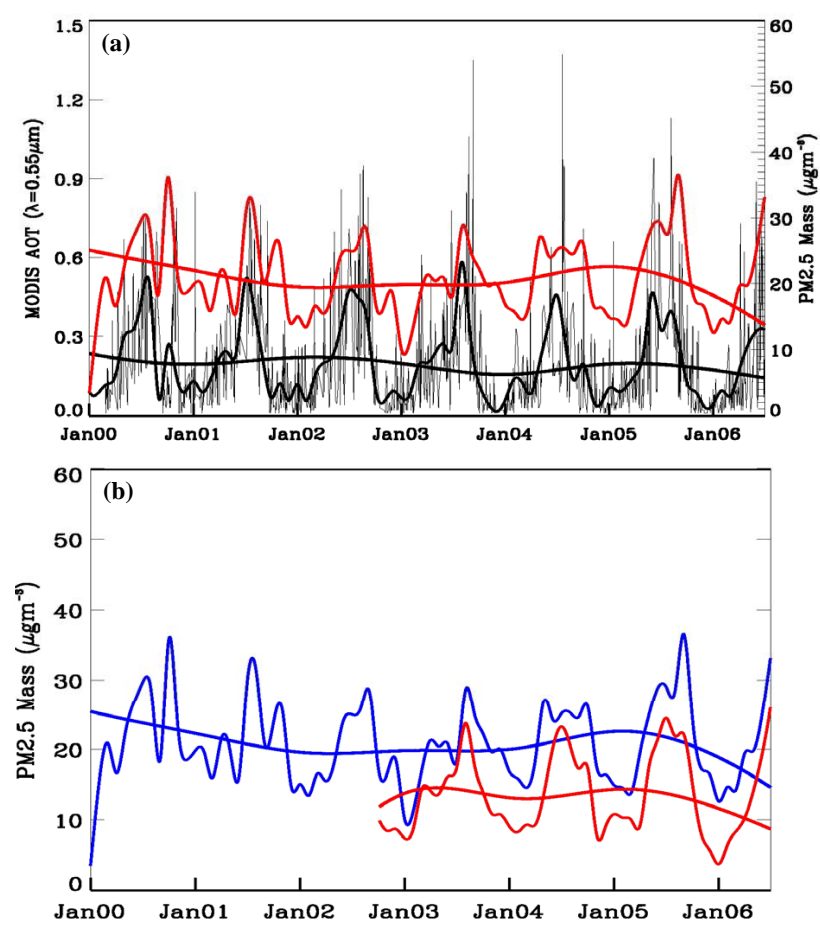

Fig. 6. Trend analysis of surface measured $\mathrm{PM}_{2.5}$ mass $(1 \mathrm{~h}$ and $24 \mathrm{~h}$ ) and MODIS AOT over the station. (a) daily, monthly and annual mean AOT as time series (black lines) and monthly and annual mean $\mathrm{PM}_{2.5}$ mass concentration (red lines). (b) monthly and annual mean $\mathrm{PM}_{2.5}$ mass obtained from $24 \mathrm{~h}$ mean $\mathrm{PM}_{2.5}$ mass data (blue lines) along with monthly and annual mean $\mathrm{PM}_{2.5}$ mass obtained from $1 \mathrm{~h}$ (during satellite overpass) $\mathrm{PM}_{2.5}$ data (red lines).

The linear correlation coefficient between $24 \mathrm{~h}$ mean $\mathrm{PM}_{2.5}$ mass concentration and MODIS AOT is 0.52 with the regression relationship given by Eq. (1).

$\mathrm{PM}_{2.5}=15.8+27.5 \times$ MODIS AOT

When a similar analysis is performed on hourly averaged $\mathrm{PM}_{2.5}$ data, the correlation increases to 0.62 and the corresponding regression equation becomes Eq. (2).

$\mathrm{PM}_{2.5}=8.8+29.4 \times$ MODIS AOT

These regression equations can be used to estimate the ground level $\mathrm{PM}_{2.5}$ mass concentration. As expected, the instantaneous MODIS AOT correlate better with hourly averaged $\mathrm{PM}_{2.5}$ compared to $24 \mathrm{~h}$ averaged $\mathrm{PM}_{2.5}$ due to diurnal variations in $\mathrm{PM}_{2.5}$ mass measurements. National Air Quality Standards are set for $24 \mathrm{~h}$ mean $\mathrm{PM}_{2.5}$ mass concentration and it is an important parameter to monitor, hence further analysis is focused only on $24 \mathrm{~h}$ mean $\mathrm{PM}_{2.5}$ and despite its moderate correlation, this relationship can estimate daily air quality categories with high degree of accuracy (Wang and Christopher et al., 2003). Several studies have shown that the relationship between $\mathrm{PM}_{2.5}$ and AOT varies substantially

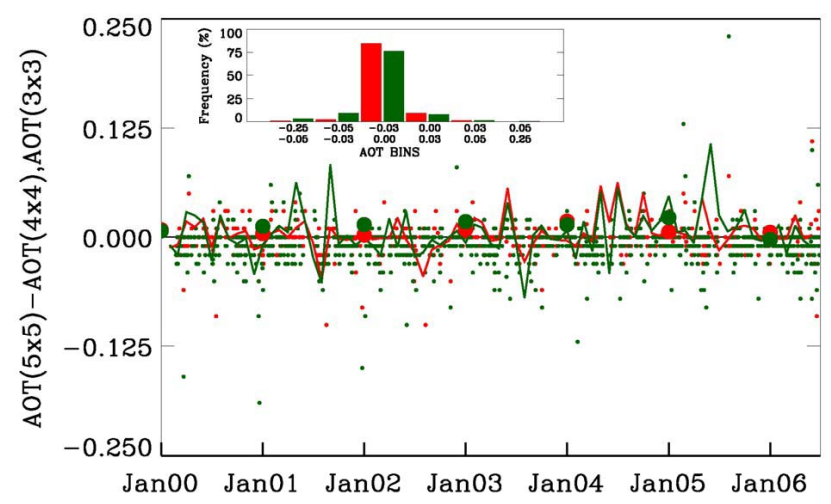

Fig. 7. Time series analysis of difference in AOTs due to change in box size around the ground station. Y-axis represents AOT5-AOT4 (red color in plot) and AOT5-AOT3 (green color in plot). Big filled circles are yearly mean, solid lines are monthly mean and small filled circles are daily AOT values. The inset panel shows frequency distribution of difference in AOTs for daily values.

Table 4. Effect of box size on AOT values at daily, monthly and yearly scales.

\begin{tabular}{cccccc}
\hline \multicolumn{6}{c}{ Daily } \\
\hline Box & Min. & Max. & Mean & Std. Dev. & Days \% \\
AOT5 & 0.010 & 1.370 & 0.198 & 0.205 & 45.049 \\
AOT4 & 0.010 & 1.370 & 0.190 & 0.201 & 41.635 \\
AOT3 & 0.010 & 1.410 & 0.185 & 0.197 & 37.000 \\
\hline \multicolumn{6}{c}{ Monthly } \\
\hline AOT5 & 0.016 & 0.583 & 0.200 & 0.136 & 47.359 \\
AOT4 & 0.019 & 0.610 & 0.196 & 0.138 & 43.680 \\
AOT3 & 0.019 & 0.652 & 0.195 & 0.139 & 38.571 \\
\hline \multicolumn{5}{c}{ Yearly } \\
\hline AOT5 & 0.156 & 0.235 & 0.196 & 0.027 & 42.818 \\
AOT4 & 0.138 & 0.226 & 0.188 & 0.030 & 39.491 \\
AOT3 & 0.142 & 0.228 & 0.184 & 0.027 & 34.873 \\
\hline
\end{tabular}

with location and time (Engel-Cox et al., 2004, Gupta et al., 2006). To further explore this variability, regression coefficients for each month and year are calculated and presented in Table 3. Yearly analysis shows that value of $r$ over different years does not vary significantly and ranges between 0.46 in 2004 and 0.60 in 2006 . Compared to yearly variations, $r$ demonstrates more variation from month to month reflecting its dependence on season. Except for December, the correlation is positive and varies from minimum of 0.08 to maximum of 0.64 . In December $r=-0.11$ and corresponds to very low AOT values (0.06). The negative correlation may be associated with large uncertainties in MODIS AOT, which can be more than $70 \%$ for AOT values less than 0.1 over land (Remer et al., 2005, Levy et al., 2007a). These low AOT's 
Table 5. Effect of quality flags on mean AOT values over the stations. Daily, monthly and yearly differences (BEST-AOT).

\begin{tabular}{lrrr}
\hline \multicolumn{4}{c}{ Daily } \\
\hline Difference & Min. & Max. & Mean \\
CN9-CN3 & -0.0800 & 0.0800 & -0.0028 \\
CN9-CN4 & -0.1100 & 0.0800 & -0.0032 \\
CN9-CN5 & -0.1100 & 0.0800 & -0.0032 \\
CN9-CN6 & -0.1100 & 0.0800 & -0.0031 \\
CN9-CN7 & -0.0700 & 0.0800 & -0.0022 \\
CN9-CN8 & -0.1100 & 0.0700 & -0.0004 \\
\hline \multicolumn{5}{c}{ Monthly } \\
\hline CN9-CN3 & -0.1120 & 0.1333 & -0.0149 \\
CN9-CN4 & -0.1158 & 0.1630 & -0.0115 \\
CN9-CN5 & -0.1158 & 0.1630 & -0.0115 \\
CN9-CN6 & -0.1158 & 0.1630 & -0.0102 \\
CN9-CN7 & -0.0606 & 0.1450 & -0.0034 \\
CN9-CN8 & -0.0545 & 0.0783 & -0.0031 \\
\hline \multicolumn{5}{c}{ Yearly } \\
\hline CN9-CN3 & -0.0411 & -0.0006 & -0.0182 \\
CN9-CN4 & -0.0426 & 0.0003 & -0.0179 \\
CN9-CN5 & -0.0426 & 0.0003 & -0.0179 \\
CN9-CN6 & -0.0380 & -0.0017 & -0.0172 \\
CN9-CN7 & -0.0199 & -0.0004 & -0.0105 \\
CN9-CN8 & -0.0124 & 0.0017 & -0.0041 \\
\hline
\end{tabular}

correspond to low $\mathrm{PM}_{2.5}$ concentrations and in general, summer and fall correlations are higher compared to winter and spring. Highest correlations are associated with mean high AOT and $\mathrm{PM}_{2.5}$ mass concentration, which is consistent with our previous analysis in other parts of the world (Gupta et al., 2006; 2007).

Intercept in regression equation represents the background levels of $\mathrm{PM}_{2.5}$ mass concentration in the absence of AOT (zero AOT). In other words, intercept represents the minimum level of particle concentration for which satellite derived AOT is sensitive. Below the level of intercept, satellite signals are weak and detection of aerosols is difficult. Value of intercept is relatively constant as a function of time and only changes between 13.7 and $16.6 \mu \mathrm{gm}^{-3}$ with mean value of $15.6 \mu \mathrm{gm}^{-3}$. In general, the intercept is greater in summer and fall months compared to winter and spring, which is also associated with high mean values of $\mathrm{PM}_{2.5}$ mass in respective months. The slope of this relationship is an important parameter for converting AOT into surface $\mathrm{PM}_{2.5}$ mass. The slope changes from 21.27 to 35.81 over different years with mean value of 27.48 . The variations in monthly slope values are large compared to yearly values and even becomes negative (-14.34) during December. Slope values could also be dependent on the local meteorological conditions as well as vertical distribution of the aerosols. Relative humidity could be an important parameter to observe while deriving these relationships because same dry $\mathrm{PM}_{2.5}$ mass concentration under different relative humidity condition can produce different AOT due to changes in scattering properties of aerosols.

\subsection{MODIS AOT, box size, and quality flags}

Satellite aerosol retrieval algorithms convert the measured reflectance to a geophysical parameter related to aerosol concentration known as AOT. There are many quality flags associated with the input data, processing methods and output data quality, which are reported in the MOD04 AOT product. The MODIS science team recommends using these quality flags along with actual AOT values for research studies. Depending on the research study, the quality flag restriction could be relaxed or stringent. In the current study, the changes in mean AOT values due to various combinations of quality flags relevant for particulate matter air quality research are examined. The effect of box size (number of pixels in spatial collocation) around the ground station on mean AOT values is quantitatively estimated for three different box sizes. Table 2 presents all nine criteria used to evaluate the change in mean AOT values at NBHM on daily, monthly and annual basis. The following discussion is separated into two parts; first, the effect of box size on mean AOT value is evaluated and then the effects of using different quality flags are discussed.

\subsubsection{Varying box size around ground station}

Criteria numbers 1 to $3(\mathrm{CN} 1$ to $\mathrm{CN} 3)$ in Table 2 use all retrieved AOT values to obtain mean AOT value over NBHM without any quality flag restrictions, but for three different box size of $5 \times 5(0.5 \times 0.5$ degrees, AOT5 $)$, $4 \times 4(0.4 \times 0.4$ degrees, AOT 4$)$, and $3 \times 3(0.3 \times 0.3$ degrees, AOT3) pixels. Decreasing box size, decreases the number of pixels used to derive MODIS AOT values for NBHM, and may affect the overall mean AOT and these can change $\mathrm{PM}_{2.5}$ estimation from satellites due to change in spatial sampling of aerosols (Hutchison et al., 2005). Larger box sizes generally indicates sampling of more heterogeneous type of aerosols, which can over or under estimate AOT values compared to point measurements from ground stations. Ichoku et al. (2002) reported that a $5 \times 5$ box is a good approximation for AOT validation with $1 \mathrm{~h}$ averaged AERONET AOT values, which is supported by arguing that average speed of aerosol transport in mid-troposphere is about $50 \mathrm{~km} / \mathrm{h}$ based on analysis of TOMS aerosol index images over the Atlantic Ocean.

However, the current focus of the study is AOT for air quality applications, which is measured at surface in the form of $\mathrm{PM}_{2.5}$ mass concentration. Since the average travel speed of aerosols (air mass) near the surface (lowest few hundred meters) is much less than mid-troposphere, one hour averaged $\mathrm{PM}_{2.5}$ measurements may not represent the air mass 
in the $50 \times 50 \mathrm{~km}$ area sampled by MODIS instrument. As a result, a smaller $3 \times 3$ box size is considered while evaluating the effects of quality flags in second part of this section. Reducing box size further might result in a statistically insignificant number of pixels and may introduce additional uncertainties. Figure 7 presents differences in daily, monthly, and annual mean AOTs due to changes in box sizes. The inset in Fig.7 contains the frequency distribution of differences in AOT4 and AOT3 values from AOT5. The difference is larger between AOT5 and AOT3 compared to AOT5 and AOT4. Daily mean differences of AOT5-AOT4 and AOT5AOT3 are -0.004 and -0.010 with ranges of -0.1 to 0.11 and -0.19 to 0.23 respectively for the entire time period. No specific trends or seasonal and annual time scales were observed when varying box sizes. Frequency distribution also shows that the difference in AOTs between -0.03 and 0.03 is observed greater than $90 \%$ of the time that is well within uncertainty limits of MODIS AOT retrievals (Levy et al., 2007a, b). Further investigation reveals that the mean of AOT5 values for which the difference is between -0.05 to 0.05 is less than 0.3 whereas it is greater than 0.45 for differences larger than 0.05 .

Therefore, it is clear that during high aerosol loading (AOT $>0.3)$ the differences in instantaneous AOT due to changes in box size could be significant while the differences are within retrieval uncertainties when aerosol loading is low $($ AOT $<0.3)$. AOT values do not change as a function of box size up to second digit of significance (Table 4). It is also important to note that, reducing box size from $5 \times 5$ to $3 \times 3$ reduces the number of available data by about $8 \%$. The regression coefficients for the AOT $-\mathrm{PM}_{2.5}$ relationship (see Sect. 4.3) are recalculated and we found that they do not change significantly as a function of box size and the number of data points. Slope values changed by less than $7 \%$, intercept by less than $0.5 \%$ and linear correlation coefficient improved by less than $2 \%$.

\subsubsection{Applying quality flags}

Criteria numbers 3 to 9 (CN3 to CN9) in Table 2 use a constant box size of $3 \times 3$ pixels around the $\mathrm{PM}_{2.5}$ station and only quality flags associated with MODIS AOT retrievals over land are changed. The primary focus of this analysis is to determine importance of the quality flags for daily, monthly and yearly aerosol analysis. We examine how much bias or uncertainty can be introduce in the AOT values if one does not use any quality flags to represent the aerosol loading.

Criteria number 9 is the most stringent in terms of quality flags and uses only good or very good retrievals, which are identified as land pixels with a solar zenith angle less than 60 degree under less than $30 \%$ cloud cover conditions. Mean AOT using CN9 are considered as best AOT (BAOT) value and all other criterions ( $\mathrm{CN} 3$ to $\mathrm{CN} 8)$ are evaluated with respect to CN9 (Table 5). A negative difference represents an

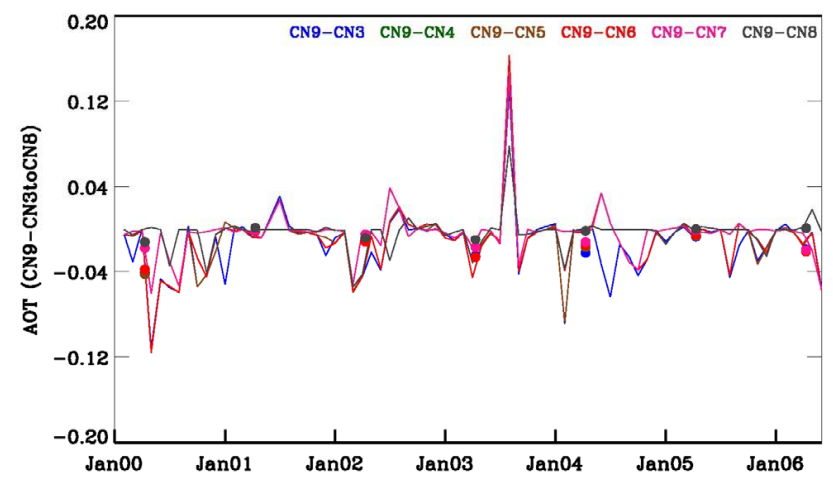

Fig. 8. Time series analysis of difference in AOTs after applying quality flags. Y-axis represents Best AOT (CN9) - all other AOTs (CN3 to $\mathrm{CN} 8$ ). Big filled circles are yearly mean, solid lines are monthly means.

overestimation in AOT. Differences in daily (instantaneous) AOT values range from -0.11 to 0.08 while mean value varies from one criterion to other. Table 5 demonstrates that the mean difference is always negative in daily, monthly and yearly analysis, which indicates an overestimation of AOT values when quality flags are not used. Figure 8 indicates that AOT values on monthly and yearly scales are generally overestimated compared to BAOT. CN4 and CN5 represent two different cases with very minor differences. CN4 does not include any cloud flags whereas CN5 restricts cloud cover above $90 \%$. AOT retrieval process and screening of unwanted pixels are such that most of the time CN4 and CN5 will have same AOT value. Differences in mean AOT values while using different criteria on daily basis are very small. The differences are larger in monthly and yearly mean values, which could arises due to sampling issues discussed in the previous section. Table 6 presents these differences for each month separately to shows seasonal variability in AOT for different criteria. Overall, there is not much seasonal dependence, but summer months (May to July) have the maximum difference while using all criteria, which could be associated with changes in cloud cover.

Figure 9 presents the reanalysis of regression equations as discussed in Sect. 4.3 with application of quality flags on AOT. The main objective of this analysis is to understand the differences in regression coefficients that can occur due to the use of different quality flags. The effect on mean number of pixels is only visible from changing box size, and it decreases as box size reduces from $\mathrm{CN} 1$ to $\mathrm{CN} 3$. We only plot all time mean values, but there could be differences in the number of pixels due to changes in quality flags over different time periods. The changes in number of pixels while using CN3 to CN9 are mainly associated with changes in cloud cover. Slope generally increases from 27.47 to 32.08 for $\mathrm{CN} 1$ to $\mathrm{CN} 9$. This could be due to the decrease in mean AOT value from $\mathrm{CN} 1$ to $\mathrm{CN}$ 9. Intercept is almost constant 
Table 6. Difference in AOTs for each criterion averaged over each month separately over entire time period.

\begin{tabular}{rrrrrrr}
\hline Month & \multicolumn{7}{c}{ Difference } \\
\hline & CN9-CN3 & CN9-CN4 & CN9-CN5 & CN9-CN6 & CN9-CN7 & CN9-CN8 \\
1 & -0.0122 & -0.0045 & -0.0045 & -0.0058 & -0.0006 & -0.0034 \\
2 & -0.0149 & -0.0151 & -0.0151 & -0.0087 & -0.0025 & -0.0057 \\
3 & -0.0131 & -0.0097 & -0.0097 & -0.0095 & -0.0079 & -0.0079 \\
4 & -0.0171 & -0.0174 & -0.0174 & -0.0177 & -0.0051 & -0.0106 \\
5 & -0.0225 & -0.0210 & -0.0210 & -0.0208 & -0.0134 & 0.0021 \\
6 & -0.0298 & -0.0196 & -0.0196 & -0.0194 & -0.0077 & 0.0001 \\
7 & -0.0155 & -0.0041 & -0.0041 & -0.0041 & 0.0045 & -0.0108 \\
8 & 0.0060 & 0.0112 & 0.0112 & 0.0112 & 0.0155 & 0.0129 \\
9 & -0.0141 & -0.0112 & -0.0112 & -0.0108 & -0.0117 & 0.0010 \\
10 & -0.0182 & -0.0175 & -0.0175 & -0.0131 & -0.0075 & -0.0009 \\
11 & -0.0179 & -0.0188 & -0.0188 & -0.0143 & -0.0013 & -0.0089 \\
12 & -0.0080 & -0.0073 & -0.0073 & -0.0072 & -0.0003 & -0.0039 \\
Mean & -0.0148 & -0.0113 & -0.0113 & -0.0100 & -0.0032 & -0.0030 \\
\hline
\end{tabular}

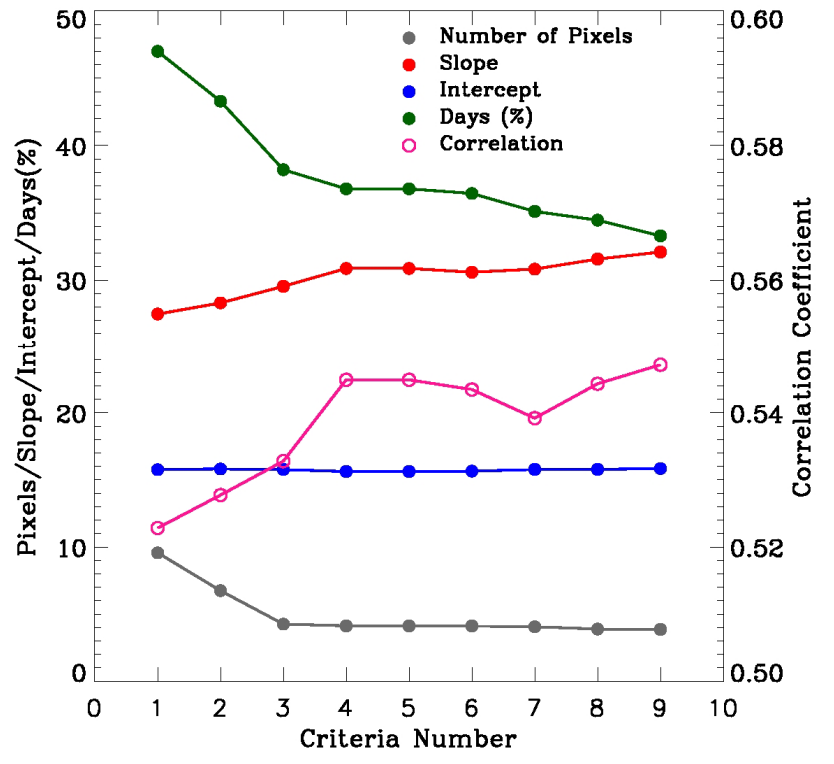

Fig. 9. Revisiting Regression Analysis using AOT from 9 different criteria.

with mean value of 15.6 , which represents a constant background $\mathrm{PM}_{2.5}$ loading over the station through out the study period. The number of days when data were available decreased from $47.0 \%$ for $\mathrm{CN} 1$ to $33.3 \%$ for CN9. However, correlation between $\mathrm{PM}_{2.5}$ and AOT does not vary significantly and only improves from 0.52 to 0.55 from $\mathrm{CN} 1$ to CN9.

\section{Summary}

Seven year surface measured $\mathrm{PM}_{2.5}$ mass concentration and MODIS-Terra derived aerosol optical thickness data sets were collected over one location in Southeastern United States (NBHM) to assess different aspects of satellite monitoring of particulate matter air quality. Surface and satellite data were analyzed to asses the long term air quality trends, availability of satellite data for air quality applications, the relationship between surface measured $\mathrm{PM}_{2.5}$ mass concentration and satellite derived integrated columnar aerosol loading (AOT) with the new generation of Collection 5 MODIS aerosol products, application of quality control flags on aerosol optical thickness values over the station, and effects on these flags on the $\mathrm{PM}_{2.5}$ - AOT relationships.

Our results indicate that NBHM air quality has improved from 2000 to 2006 with unhealthy conditions during summer when compared to other seasons. Since satellites can provide particulate matter air quality information only during cloud-free and favorable surface conditions we calculated the availability of satellite data for this station. A significant conclusion of this study is that even though NBHM is sampled only $50 \%$ of the time by Terra-MODIS, the monthly, seasonal and yearly means are different only by $2 \mu \mathrm{gm}^{-3}$ when compared to using a $100 \%$ data availability rate from ground measurements. Our analysis of quality control flags and box sizes for evaluating $\mathrm{PM}_{2.5}$-AOT relationships indicate that for daily analysis using quality control flags are critical but for monthly and yearly analysis these flags may not be necessary. Finally, quality flags also do not affect the $\mathrm{PM}_{2.5}$-AOT relationship significantly but reduces the available satellite data by up to $14 \%$ from all retrievals to best retrievals. Hence depending on the requirement of sample size as well as accuracies, quality flags can be used or ignored. These results indicate that satellite data can be a powerful tool for evaluating air quality in regions especially when ground measurements 
are not available. Direct extrapolation of results from this study to other regions may not be possible without further analysis.

Acknowledgements. This research is supported by NOAA Air quality projects at UAH (NA06NES4400008 and NA07NES42800005). Pawan Gupta was supported by NASA Headquarters under the Earth and Space Science Fellowship (NESSF) Grant. MODIS data were obtained from the Level 1 and Atmosphere Archive and Distribution System (LAADS) at Goddard Space Flight Center (GSFC). $\mathrm{PM}_{2.5}$ data were obtained from EPA's Air Quality System (AQS). We thank Thomas Jones for his editorial work and for a critical reading of this manuscript.

Edited by: F. J. Dentener

\section{References}

Abdou, W. A., Diner, D. J., Martonchik, J. V. Bruegge, C. J., Kahn, R. A., Gaitley, B. J., Crean, K. A., Remer, L. A., and Holben, B.: Comparison of coincident Multiangle Imaging Spectroradiometer and Moderate Resolution Imaging Spectroradiometer aerosol optical depths over land and ocean scenes containing Aerosol Robotic Network sites, J. Geophys. Res., Atmos., 110(D10), D10S07, 11967-76, 2005.

Ackerman, S., Strabala, K., Menzel, P., Frey, R., Moeller, C., and Gumley, L.: Discriminating clear sky from clouds with MODIS, J. Geophys. Res., 103(32), 141-157, 1998.

Al-Saadi, J., Szykman, J., Pierce, R. B., Kittaka, C., Neil, D., Chu, D. A., Remer, L., Gumley, L., Prins, E., Weinstock, L., Macdonald, C., Wayland, R., Dimmick, F., and Fishman, J.: Improving National Air Quality Forecasts With Satellite Aerosol Observations, Bulletin Of The American Meteorological Society, 86(9), 49-1261, 2005.

Chu, D. A., Kaufman, Y. J., Zibordi, G., Chern, J. D., Mao, J., Li, C., and Holben, B. N.: Global monitoring of air pollution over land from the Earth Observing System-Terra Moderate Resolution Imaging Spectroradiometer (MODIS), J. Geophys. Res., 108(D21), 4661, doi:10.1029/2002JD003179, 2003.

Donkelaar, A., Martin, R. V., and Park, R. J.: Estimating ground-level $\mathrm{PM}_{2.5}$ using aerosol optical depth determined from satellite remote sensing, J. Geophys. Res., 111, D21201, doi:10.1029/2005JD006996, 2006.

Engel-Cox, J. A., Hoff, R. M., Rogers, R., Dimmick, F., Rush, A. C., Szykman, J. J., Al-Saadi, J., Chu, D. A., and Zell, E. R.: Integrating lidar and satellite optical depth with ambient monitoring for 3-dimensional particulate characterization, Atmos. Environ., 40, 8056-8067, 2006.

Engel-Cox, J. A., Christopher H. H., Coutant, B. W., and Hoff, R. M.: Qualitative and quantitative evaluation of MODIS satellite sensor data for regional and urban scale air quality, Atmos. Environ., 38, 2495-2509, 2004

Gupta, P., Christopher, S. A., Box , M. A., and Box, G. P.: Multi year satellite remote sensing of particulate matter air quality over Sydney, Australia. International J. Remote Sensing, 28(20), 4483-4498, doi:10.1080/01431160701241738, 2007.

Gupta, P., Christopher, S. A., Wang, J., Gehrig, R., Lee, Y. C., and Kumar, N.: 2006, Satellite remote sensing of particulate matter and air quality over global cities, Atmos. Environ., 40(30), 5880 5892, 2006.

HEI : Health effects of outdoor air pollution in developing countries of Asia: a literature review, edited by: HEI, International Oversight Committee, Boston, MA, USA, Health Effects Institute, Special Report No. 15, 2004.

Hess, M., Koepke, P., and Schult, I.: Optical Properties of Aerosols and clouds: The software package OPAC, Bulletin of the American Meteorological Society, 79, 831-844, 1998.

Hsu, N. C., Tsay, S. C., King, M. D., and Herman, J. R.: Aerosol retrievals over bright-reflecting source regions, IEEE Trans. Geosci. Remote Sens., 42, 557-569, 2004.

Hubanks, P. A., Chu, A., Ridgway, B., Strabala, K., Platnick, S., Mattoo, S., Moody, E., King, M. D., and Hucek, R.: MODIS Atmosphere QA Plan for Collection 005 (Deep Blue Aerosol Update), http://modis-atmos.gsfc.nasa.gov/reference_atbd.php), 3.5, 2007.

Hussein, T., Karppinen, A., Kukkonen, J., Härkönen, J., Aalto, P. P., Hämeri K., Kerminen, V., and Kulmala, M.: Meteorological dependence of size-fractionated number concentrations of urban aerosol particles, Atmos. Environ., 40, 1427-1440, 2006.

Hutchison, K. D., Smith, S., and Faruqui, S.: Correlating MODIS aerosol optical thickness data with ground-based $\mathrm{PM}_{2.5}$ observations across Texas for use in a real-time air quality prediction system, Atmos. Environ., 39, 7190-7203, 2005.

Ichoku, C., Chu, D. A., Mattoo, S., Kaufman, Y. J., Remer, L. A., Tanré, D., Slutsker, I., And Holben, B. N.: A spatio-temporal approach for global validation and analysis of MODIS aerosol products, Geophys. Res. Lett., 29(12), 8006, doi:10.1029/2001GL013206, 2002.

Kahn, R. A., Gaitley, B. J., Martonchik, J. V., Diner, D. J., and Crean, K. A.: Multiangle Imaging Spectroradiometer (MISR) global aerosol optical depth validation based on 2 years of coincident Aerosol Robotic Network (AERONET) observations, J. Geophys. Res., 110, D10S04, doi:10.1029/2004JD004706, (2005).

Krewski, D., Burnett, R. T., Goldberg, M. S., Hoover, K., Siemiatycki, J., Jerrett, M., Abrahamowicz, A. and White, W. H.: Reanalysis of the Harvard Six Cities Study and the American Cancer Society Study of Particulate Air Pollution and Mortality, A Special Report of the Institute's Particle Epidemiology Reanalysis Project, Health Effects Institute, Cambridge MA, 97 pp., 2000.

Kukkonen, J., Pohjola, M., Sokhi, R. S., Luhana, L., Kitwiroon, N., Fragkou, L., Rantamäki, M., Berge, E., Ødegaard, V., Slørdal, L. H., et al.: Analysis and evaluation of selected local-scale $\mathrm{PM}_{10}$ air pollution episodes in four European cities: Helsinki, London, Milan and Oslo, Atmos. Environ., 39, 2759-2773, 2005.

Levy, R. C., Remer, L. A., Dubovik, O.: Global aerosol optical properties and application to Moderate Resolution Imaging Spectroradiometer aerosol retrieval over land, J. Geophys. Res., 112, D13210, doi:10.1029/2006JD007815, $2007 \mathrm{~b}$.

Levy, R. C., Remer, L. A., Mattoo, S., Vermote, E. F., Kaufman, Y. J.: Second-generation operational algorithm: Retrieval of aerosol properties over land from inversion of Moderate Resolution Imaging Spectroradiometer spectral reflectance, J. Geophys. Res., 112, D13211, doi:10.1029/2006JD007811, 2007a.

Liu, Y., Park, R. J., Jacob, D. J., Li, Q., Kilaru, V., and Sarnat, J. A.: Mapping annual mean ground-level $\mathrm{PM}_{2.5}$ concentrations using Multiangle Imaging Spectroradiometer aerosol optical thick- 
ness over the contiguous United States, J. Geophys. Res., 109, D22206, doi:10.1029/2004JD005025, 2004.

Martins, J. V., Tanr'e, D., Remer, L. A., Kaufman, Y. J., Mattoo, S., and Levy, R.: MODIS Cloud screening for remote sensing of aerosol over oceans using spatial variability, Geophys. Res. Lett., 29, MOD04, doi:10.1029/2001GL013252, 2002.

Pelletier, B., Santer, R., and Vidot, J.: Retrieving of particulate matter from optical measurements: A semiparametric approach, J. Geophys. Res., 112, D06208, doi:10.1029/2005JD006737, 2007.

Pope, C. A. III. and Dockery, D. W.: Health Effects of Fine Particulate Air Pollution: Lines that Connect, J. Air Waste Manage. Assoc., 56, 709-742, 2006.

Pope, C. A.: Epidemiology of Fine Particulate Air Pollution and Human Health: Biologic Mechanisms and Who's at Risk? Env. Health Persp., 104, 713-723, 2000.

Pope, C. A. III., Burnett, R. T., Thun, M. J., Calle, E. E., Krewski, D., Ito, K., and Thurston, G. D.: Lung Cancer, Cardiopulmonary Mortality, and Long-Term Exposure to Fine Particulate Air Pollution, J. Am. Med. Assoc., 287, 1132-1141, 2002.
Prados, A. I., Kondragunta, S., Ciren, P., and Knapp K. R.: GOES Aerosol/Smoke Product (GASP) over North America: Comparisons to AERONET and MODIS observations, J. Geophys. Res., 112, D15201, doi:10.1029/2006JD007968, 2007.

Remer, L. A., Kaufman, Y. J., Tanré, D., Mattoo, S., Chu, D. A., Martins, J. V., Li, R. R., Ichoku, C., Levy, R. C., Kleidman, R. G., Eck, T. F., Vermote, E., and Holben, B. N.: The MODIS Aerosol Algorithm, Products and Validation, J. Atmos. Sci., 62, 947-973, 2005.

Wang, J. and Christopher, S. A.: Intercomparison between satellitederived aerosol optical thickness and $\mathrm{PM}_{2.5}$ mass: Implications for air quality studies, Geophys. Res. Lett., 30(21), 2095, doi:10.1029/2003/GL018174, 2003.

Wang, J. and Martin, S. T.: Satellite characterization of urban aerosols: Importance of including hygroscopicity and mixing state in the retrieval algorithms, J. Geophys. Res., 112(D17), D17203, doi:10.1029/2006JD008078, 2007. 